\title{
The Practicality of using Indigenous Language (Nsenga) as Medium of Instructing at Grade 1-4 in Selected Primary Schools of Petauke District
}

\author{
Tembo Gerald Major ${ }^{1}$, Nyimbili Friday ${ }^{2}$ \\ ${ }^{1}$ Holder of a Masters Degree in Education Management \\ ${ }^{2}$ Ph.D. student in Applied Linguistics at the University of Zambia
}

\begin{abstract}
*Corresponding Author: Tembo Gerald Major, Holder of a Masters Degree in Education Management
\end{abstract}
\begin{abstract}
The purpose of this study is to investigate the practicality using Nsenga language in the primary schools of Petauke district. The study objectives were to establish the teachers' perception on the implementation of the use of familiar language and to assess the benefits of using Nsenga as a language of instructions in the primary schools Petauke District. The study used a mixed methods approach and collected data from 30 teachers from five primary schools using interview guide and a questionnaire. The study concluded that the teachers' perception on the implementation of the use of familiar language in selected Primary Schools in Petauke District was positive because the usage of Cinyanja as an instructional language was high in the primary schools due to the policy restriction while the usage of Nsenga as an instructional language was as high due to the sociolinguistic situation in the classrooms and this lead to the teachers and learners preferring to use Nsenga as their language of instruction. The realised benefits of the use of Nsenga in the teaching to the Nsenga learners provided the learners with the practical understanding of the content the teacher was teaching about. The other benefits were that teachers were forced to use Nsenga in their teaching because learners provided answers in Nsenga instead of the Cinyanja which was not familiar to them. This then leaves space to enhance translanguaging in such schools so as to realise the full potential of the learners and their languages as Nsenga has proved its practicality in teaching learners.
\end{abstract}

Keywords: Nsenga language, Petauke district, indigenous language of instruction

\section{INTRODUCTION}

The manner in which language is actually used during instruction is important for understanding educational outcomes in a multilingual developing country like Zambia. As a result, curriculum reform has been at the centre of activities deemed vital to transform society and raise student's learning and achievement. The Zambian education system has not been an exception to this phenomenon. With the advent of independence numerous attempts were made to reform the curriculum and make it more responsive to the country's need in terms of churning out functional and articulate school graduates (MOE, 2013).

Phiri (2013) noted that the curriculum we have been using in our schools is what our political freedom fighters had put in place after the attainment of independence in 1964 and it was based on the 1966 Education Act. Due to the passage of time and changes in social economic political and technological life, our school curriculum had become archaic and required serious attention. This was a statement as a minister of education that provided the rationale for the emergence of the 2013 New Language of Play policy (NLP) in Zambia which was advocating for the use of familiar languages as medium of instruction from grades 1 - 4. While all government schools applied the Primary Reading Program (PRP) towards enhancing the use of a familiar language for initial literacy in grade one.

MOESVTEE (2013) state that the main aim of the curriculum was to equip learners with skills, knowledge and values to read and write in order to contribute meaningfully to the development of society and the economy. The new framework was arrived at through a long process of consultation and participation by stakeholders such as the reports from the vision 2030, education act 2011, national development plans and education policy 1996 (MOESVTEE, 2013). The implementation 
plan was to be done in phases.In 2014, the implementation plan was at grade 1, in 2015 at grade 2, 2016 at grade 3 and 2017 at grade 4. Despite this implementation plan, the literacy of instruction in Petauke, Chewa, is not intelligible with Nsenga which is the language of play by the learners in Petauke. Mkandawire (2017) argue that the classroom sociolinguistics in most urban and rural areas of Lusaka was diverse and needed the teacher to understand what the learners' language were before imposing a language on them. Nyimbili (2017) also noted that the teaching of language is affected by many factors which make the challenges become real and hinder learning in classrooms. This understand is the first step to literacy development.

The concept of having regional languages to teach learners has been criticised by Mwanza (2020) for being faulty because the regional languages do not represent the actual languages of play and community languages available in the different Zambian communities. Banda and Mwanza (2017) recommended translanguaging as the most suitable language practice in the multilingual classrooms of Zambia. They argued that translanguaging would liberate the classroom by connecting the home and the school. In fact, based on similar findings, Mwanza (2020) argues that while several factors account for the low literacy levels in Zambia, the symbolic violence which is reproduced in the classrooms is the major explanation for the low literacy achievements in Zambia. To justify the need for translanguaging in the teaching of literacy to learners in communities where the language of instruction is not the familiar language, Nyimbili and Mwanza (2020) record that there are better benefits of using translanguaging than using the monolingual ideologies that are not progressive in such classrooms as experimented in Lundazi district.

Mwanza (2017) argued that Zambia's bilingual language policy was the reason because it was premised on monolingual/monoglot language ideologies that Cummins (2009) describes as a policy where learners receive instruction in one language until when they were thought to have mastered the target language in order to receive instruction in the second language. In its practical manifestation, the Zambian language of initial literacy policy is what Garcia (2009) calls two solitudes. In fact, findings from Tambulukani (2014), Mwanza (2012) and Zimba (2011) have provided sufficient evidence that using monolingual practices in the Zambian multilingual classrooms was a contributing factor to the low literacy levels in Zambia and what the policy recommended did not match with the language practices of the local people.

Nyimbili and Mwanza (2021) argue that the use of a regional language to cater for linguistic grouping in a province and across districts does not represent the real sociolinguistic that exist in the communities, schools and homes where the learners come from. They argue that the teaching of literacy to learners whose first language of instruction is not the regional language is faced with the failure to use the teaching and learning materials effectively as they are in a different language alien to the learners. They also argue that the classroom sociolinguistic environment does not favour the use of the community language and the policy does not allow such, the assessment is imposed in the regional language which is not in the community, the language have phonological and phonemic differences and the curriculum is premised on monolingual ideologies.

Despite such findings, the MOE (2014:17) states that “.....since learners come from different language backgrounds, it is very important that teachers conduct oral language lessons in order to expand their learners' working vocabulary in familiar languages which are used for instruction." This policy theoretically recognises familiar languages but practically points to monolingual regionalisation of language teaching. Therefore, in practice, this policy statement does not support the learner's local languages but points back to the regional language which is the language of instruction (Cinyanja). Therefore, the social environment to allow translanguaging to take place is not supported in the monolingual policy promoted Zambian schools.

In another study by Nyimbili and Mwanza (2020) that looked at quantitative and qualitative benefits of translanguaging pedagogical practices amongst first graders in Lundazi district, the study brings important literature to this study. the study found the Post experimental test results showed higher average mean scores for the experimental group $(\mathrm{M}=15.10)$ than the control group $(\mathrm{M}=11.71)$. The Cohen's $\mathrm{d}=0.98$ for the post-test showed the large effect size above .8 . The performance of learners in the experimental group was significantly different from the control group [ $\mathrm{t}(52.960=4.454$, $\mathrm{p}<0.001]$. Thus, the difference in literacy performance can be attributed to the translanguaging 
practices which were used to teach literacy in the experimental class. Additional results showed that as a result of translanguaging, there was increased learner classroom participation, multiliteracy development, cultural preservation and learners' identity affirmation. The study concludes that when the curriculum is decolonised and the classroom is liberated through recognition of learners' linguistic repertoires, learning outcomes improve. Such benefits were significant to the uplifting the teaching and learning of literacy using the local language as it brought about linguistic reinforcement to the learners and literacy improvement as the curriculum and syllabus aims.

Other studies have also proved the point that teachers and learners face challenges in the teaching and learning of literacy using regional languages instead of the community language. Phiri (2012) indicated that the language of instruction to a larger extent was a barrier both to learners and teachers. The situation was more pronounced in urban and in peri-urban schools because of the factor of multilingualism which made it impracticable to use a regional standard language (Kaonde) as a medium of instruction in New Breakthrough to Literacy. The Kaonde orthography was different from the Kaonde they spoke in the urban. Simachenya (2017) too found that in a Tonga regional language classroom, the classroom sociolinguistics wascharacterised by Nyanja instead of the language of instruction. It is clear that Nyanja was preferred by learners to enable them to contribute freely during lessons in a way of responding to the oral questions from their teachers. This means that some learners in the selected primary schools of Livingstone Urban opted to respond to their teachers in Nyanja in order for them to be fully part of the learning process.

Further, Chinyama (2016) revealed that when teachers used Bemba to speak to the learners or give instructions, the learners failed to respond unless the teachers translated into Namwanga. In all these instances, it can be viewed that teachers were facing challenges in teaching literacy to learners who first language is not the language of instruction. It is with this background that the current study seeks to investigate the challenges faced by teachers in the implementation of new policy of using familiar language as medium of instruction from grade 1 - 4; case of selected primary schools in Petauke district.

\subsection{Purpose of the Study}

The purpose of this study is to investigate the practicality using Nsenga language in the primary schools of Petauke district.

\subsection{Objectives}

i. To establish the teachers' perception on the implementation of the use of familiar language in selected Primary Schools in Petauke District

ii. To assess the benefits of using Nsenga as a language of instructions in the primary schools Petauke District.

\section{Methodology AND Materials}

The study adopted a mixed methods approach and used a convergent design to collect data in the primary schools of Petauke district. The sample for the study was 30 teachers their learners in class. The study collected data using interviewing teachers in five schools who taught different subjects at the lower primary level. The study ensured that participants were protected by not mentioning them, an informed consent was also signed while their responses were kept as a secrete until after publication that was when access to the document was provided. Qualitative data was analysed thematically by first, transcribing the recorded interviews, coding data and then presenting data using verbatims to ensure the meaning and quality of responses is maintained. Quantitative data was entered into SPSS and descriptive statistics was run which provided frequency table used to present and understand the research findings.

\section{FINDINGS OF THE STUDY}

\subsection{Teachers' Perception on the Implementation of the use of Familiar Language in Selected Primary Schools}

Data for this research question was collected using a questionnaire which teachers answered in the various schools sampled for the study. 
The Practicality of using Indigenous Language (Nsenga) as Medium of Instructing at Grade 1-4 in Selected Primary Schools of Petauke District

\subsubsection{Average Zambian Language Diversity in Respondents' Classrooms}

Classroom mother tongue diversity was examined in individual classrooms manned by the 30 respondents. It was deduced that Cinyanja comprised the highest number with an average 23 pupils representing $52.3 \%$ of the class. Bemba ranked secondary with an average of $9(20.5 \%)$ of pupils. Chitonga, Lozi and Lunda ranked third, fourth and fifth with $5(11.3 \%), 3(6.8 \%)$ and $2(4.5 \%)$ respectively. Kikaonde and Luvale occurred as the least represented each with an average number of 1 (2.3\%) pupil per class. Table 3.1.1 below summarises the average classroom diversity based on the 7 major Zambian languages:

Table3.1.1. Mother Tongue Diversity amongst Pupils

\begin{tabular}{|l|l|l|}
\hline Mother Tongue & Frequency (No. of Respondents) & Percentage (\%) \\
\hline Very High & 1 & 3.3 \\
\hline High & 10 & 33.3 \\
\hline Average & 13 & 43.3 \\
\hline Low & 4 & 13.3 \\
\hline Very Low & 2 & 6.8 \\
\hline TOTAL & $\mathbf{3 0}$ & $\mathbf{1 0 0 \%}$ \\
\hline
\end{tabular}

The language in the classroom were diverse and the learners did not come from the regional language speaking community, Cinyanja, but mixed. The findings are supported by Mkandawire (2017) who also found that the classroom sociolinguistics was diverse and needed the teacher to understand what the learners' language were before imposing a language on them. This diversity was a hinderance to classroom participation since learners could not use their local language to interact with the learning content in such classes. This result into failed literacy instruction as it is tied to regional language which is practically different from the learners' language of play.

\subsubsection{Teachers Levels of Fluency in the Familiar language}

The table below summarises the findings in terms of the teachers' levels of fluency in the familiar language (Nsenga):

Table3.1.2. Teachers Levels of Fluency in Familiar Language

\begin{tabular}{|l|l|l|}
\hline Level of Fluency in Nsenga & Frequency (No. of Respondents) & Percentage (\%) \\
\hline Very high & 05 & 16.7 \\
\hline High & 10 & 33.3 \\
\hline Average & 12 & 40.0 \\
\hline Low & 02 & 6.7 \\
\hline Very low & 01 & 3.3 \\
\hline TOTAL & $\mathbf{3 0}$ & $\mathbf{1 0 0}$ \\
\hline
\end{tabular}

The 30 respondent teachers were ranked on a five point scale in terms of their levels of fluency the dominant familiar language (i.e. Nsenga) of the study area. The fluency was on the basis of ability to speak, read and write in the familiar language. The ranking was from very high to very low in terms of how each teacher perceived the fluency. $5(16.7 \%)$ of the teachers stated that they had a very high fluency in the familiar language. A significant number of respondents that is, 22 respondents stated that they had a fluency level of high and average with the actual figures standing at $10(33.3 \%)$ and 12 $(40.0 \%)$ of the respondents respectively. Whereas 3 respondents (i.e. 2 ranked low and 1 ranked very low) occurred at the modest end of fluency rankings in familiar language fluency.

\subsubsection{Usage of Cinyanja as an Instructional Language}

The usage of Cinyanja as a language of instruction was evaluated on a five point scale. It was deduced that all the 30 respondents ranked above average when it came to the use of Cinyanja as a language of instruction. $5(16.7 \%)$ of the respondents were rated at very high users of Cinyanja as a language of instruction. $16(53.3 \%)$ of the respondents were ranked as being high users of Cinyanja. The remaining 9 out of the $30(30.0 \%)$ respondents were ranked as being average users of Cinyanja in class. Table 4.3.2 below gives a summary of these findings: 
The Practicality of using Indigenous Language (Nsenga) as Medium of Instructing at Grade 1-4 in Selected Primary Schools of Petauke District

Table3.1.3. Usage of Cinyanja as a Language of Instruction

\begin{tabular}{|l|l|l|}
\hline Level of Cinyanja usage & Frequency (No. of Respondents) & Percentage (\%) \\
\hline Very high & 05 & 16.7 \\
\hline High & 16 & 53.3 \\
\hline Average & 09 & 30.0 \\
\hline Low & 00 & 0.0 \\
\hline Very low & 00 & 0.0 \\
\hline TOTAL & $\mathbf{3 0}$ & $\mathbf{1 0 0}$ \\
\hline
\end{tabular}

3.1.4. Usage of a Combination of Cinyanja and English as an Instructional Language

The 30 respondents were asked to rate themselves on the basis of using a combination of Cinyanja and English as a language of instruction in their classes. The results show that 3 respondents occurred with $1(3.3 \%)$ respondent ranked as very high and $2(6.7 \%)$ respondents ranked as high in terms of Cinyanja and English usage for class instruction. 17 (56.7\%) of the respondents were ranked as being average users of Cinyanja and English in class instruction. The remaining 10 (33.3\%) out of the 30 respondents were ranked as using Cinyanja and English at a low level. At the very low Cinyanja and English usage no respondent $\mathrm{s}$ occurred there. The table below (Table 4.3.3) summarises these findings:

Table3.1.4. Usage of Cinyanja and English as a Language of Instruction

\begin{tabular}{|l|l|l|}
\hline Level of Cinyanja and English usage & Frequency (No. of Respondents) & Percentage (\%) \\
\hline Very high & 01 & 3.3 \\
\hline High & 02 & 6.7 \\
\hline Average & 17 & 56.7 \\
\hline Low & 10 & 33.3 \\
\hline Very low & 00 & 0.0 \\
\hline TOTAL & $\mathbf{3 0}$ & $\mathbf{1 0 0}$ \\
\hline
\end{tabular}

\subsubsection{Usage of Nsenga as an Instructional Language}

The respondents were evaluated on the intensity of using Nsenga in classroom instruction. The results show that of the 30 respondents, $20(66.7 \%)$ of the respondents were ranked as very high users of Nsenga in classroom instruction. $5(16.7 \%)$ of the respondents were ranked as being high users of Nsenga in classroom instruction. 4 (13.3\%) and 1 (3.3\%) of the respondents were ranked as being average and low users of Nsenga as a language of instruction respectively. No respondents $(0.0 \%)$ occurred on the very low Nsenga usage ranking in classroom instruction. Table 4.3.4 below summarises these findings:

Table3.1.5. Usage of Nsenga as a Language of Instruction

\begin{tabular}{|l|l|l|}
\hline Level of Nsenga usage & Frequency (No. of Respondents) & Percentage (\%) \\
\hline Very high & 20 & 66.7 \\
\hline High & 05 & 16.7 \\
\hline Average & 04 & 13.3 \\
\hline Low & 01 & 3.3 \\
\hline Very low & 00 & 0.0 \\
\hline TOTAL & $\mathbf{3 0}$ & $\mathbf{1 0 0}$ \\
\hline
\end{tabular}

\subsubsection{Instructional Language Preferences of Teachers}

The 30 respondents were evaluated in terms of their preferences of instructional language used in the classroom. $15(50 \%)$ of the respondents preferred to use Cinyanja as their main language of instruction. $13(43.3 \%)$ of the respondents stated that they preferred to use Nsenga as their language of instruction. When it came to the use of English as the preferred language of instruction, 2 (6.7\%) of the respondents acknowledged a preference for English. None of the respondents $(0.0 \%)$ preferred the use of any other instructional languages which is an exception to three identified (Cinyanja, Nsenga and English). Table 4.3.6 below summarise these findings: 
The Practicality of using Indigenous Language (Nsenga) as Medium of Instructing at Grade 1-4 in Selected Primary Schools of Petauke District

Table3.1.6. Respondents preferred Instructional Language

\begin{tabular}{|l|l|l|}
\hline Preferred Instructional Language & Frequency (No. of Respondents) & Percentage (\%) \\
\hline Cinyanja & 15 & 50.0 \\
\hline Nsenga & 13 & 43.3 \\
\hline English & 2 & 6.7 \\
\hline Other & 0 & 0.0 \\
\hline TOTAL & $\mathbf{3 0}$ & $\mathbf{1 0 0}$ \\
\hline
\end{tabular}

3.2. Benefits of using Nsenga as a Language of Instructions in the Primary Schools Petauke District

The benefits of using Nsenga as a language of instructions in the primary schools Petauke District was perceived to be enormous in the primary schools. The participants revealed that the use of Nsenga in the teaching of literacy to the Nsenga learners provided the learners with the practical understanding of the content the teacher was teaching about. In other words, using Nsenga provided a way of making learners see the content being taught from their local environment point of view. One participant said:

I came to realise that when I used Nsenga in my teaching, learners were participating than when I used Cinyanja consistently. This then made me realise that my learners were not participating because the language of instruction was different from the language of play.

Another participant said:

Language in class was a factor to the learning in this community. When I teach my lessons in Cinyanja, my learners were not active and after giving them work, the performance was rather poor. But when I use Nsenga, they became active, and performance was actually better.

From the foregoing, learners were comfortable to learn classroom content using their local language unlike the regional language.

It was also established that teachers were forced to use Nsenga in their teaching of literacy because learners provided answers in Nsenga instead of the Cinyanja which was not familiar to them. It was also learnt that when the teacher used Cinyanja to ask questions to the class, the learners would use Nsenga to ask the teacher to rephrase the question in a simper language they could understand. one participant said:

My learners are familiar with Nsenga and not Cinyanja. When I ask a question which needs their response, they respond in Nsenga giving me the correct answer. This show me that Cinyanja was not easy for them in my class.

Another participant added that:

At times, I ask the same question in two languages, Nsenga and Cinyanja that is when they understand what I am talking about. Despite asking in two languages, the responses are always in Nsenga instead of Cinyanja.

Participants also noted that when Nsenga was used in the teaching, learners became interested in their local language, and they wrote their language more than Cinyanja. This can be linked to the emergent literacy development which the learners have, and the regional language want to supress. It was learnt that at about grade two, learners were writing Nsenga words fluently while they also wrote Cinyanja words. One participant said:

The combination of Cinyanja and Nsenga in the teaching of learners in the primary school has brought about literacy development of learners in their local language as well as the language of instruction. Learners are now able to write in both languages which is good. 
The Practicality of using Indigenous Language (Nsenga) as Medium of Instructing at Grade 1-4 in Selected Primary Schools of Petauke District

Another participant said:

The combination of languages in class has made the learners to realise the need for them use their language in home and school. This has resulted into them writing words in both languages independently which is good.

These benefits are better for the development of the Nsenga culture at the expense of making the learners acquire the regional language which was difficult.

\section{DISCUSSION OF FINDINGS}

The language in the classroom according to table 3.1.1 were diverse and the learners did not come from the regional language speaking community, Cinyanja, but mixed. The findings are supported by Mkandawire (2017) who also found that the classroom sociolinguistics was diverse and needed the teacher to understand what the learners' language were before imposing a language on them. This diversity was a hinderance to classroom participation since learners could not use their local language to interact with the learning content in such classes. This result into failed literacy instruction as it is tied to regional language which is practically different from the learners' language of play.

The study findings in table 3.1.3 show that the usage of Cinyanja as an instructional language was high in the primary schools. This cannot be disputed because the language of instruction is Cinyanja hence it has to dominate in class. However, table 3.1.5 show that the usage of Nsenga as an instructional language was as high as $20(66.7 \%)$ (very high) and $5(16.7 \%)$ of the respondents were ranked as being high users of Nsenga in classroom instruction. This also coincide with table 3.1.6 where $15(50 \%)$ of the respondents preferred to use Cinyanja as their main language of instruction. 13 $(43.3 \%)$ of the respondents stated that they preferred to use Nsenga as their language of instruction. These findings are supported by Phiri (2012) who indicated that the regional language of instruction to a larger extent was a barrier both to learners and teachers. In such circumstances, Simachenya (2017) add that in a Tonga regional language classroom, the classroom sociolinguistics was characterised by Nyanja instead of the language of instruction. It is clear that Nyanja was preferred by learners to enable them to contribute freely during lessons in a way of responding to the oral questions from their teachers. Further, Chinyama (2016) also revealed that when teachers used Bemba to speak to the learners or give instructions, the learners failed to respond unless the teachers translated into Namwanga.

From the foregoing, it canbe argued that the Zambian sociolinguistics in the community has affected the classroom as well because regions and districts nolonger have one language to sustain the community for communication and interaction. This is realised from the way the learners' languages have been distributed in class and the teachers' linguistic familiarity which at play. as much as the teachers are not from the regional language speaking community, their knowledge of such a language end at the academic level only. This then confirms what other scholars like Nyimbili and Mwanza (2020) stated that regional languages are no longer influential in the primary school classrooms of today as their languages are not having a place in the school curriculum especially in eastern province of Zambia. To this, they recommended the use of translanguaging to enable the minority in the linguistic representation be able to have epistemic access in Zambian schools.

The study also established that the benefits of the use of Nsenga in the teaching of literacy to the Nsenga learners provided the learners with the practical understanding of the content the teacher was teaching about. In other words, using Nsenga provided a way of making learners see the content being taught from their local environment point of view. Nyimbili and Mwanza (2021) support these findings when they found that the difference in literacy performance can be attributed to the translanguaging practices which were used to teach literacy in the experimental class. They further argue that the benefits of translanguaging were increased learner classroom participation, multiliteracy development, cultural preservation and learners' identity affirmation. The use of one language of instruction in this study reflect the lack of understanding that the community is changing and so is the linguistic situation in all communities. By these findings presented, it is clear that the learners in Petauke district were benefiting from the teachers' ability to put away the policy guidelines in language teaching and learning in primary schools and respond to the needs of the learners by making them realise that even their language is important to their learning. Such initiatives have to be 
appreciated as the failure by these learners in pointed to the teacher instead of the colonial and rigid policy that restrict teachers to teach primary school learners using regional languages.

It was also established in the study that teachers were forced to use Nsenga in their teaching of literacy because learners provided answers in Nsenga instead of the Cinyanja which was not familiar to them. It was also learnt that when the teacher used Cinyanja to ask questions to the class, the learners would use Nsenga to ask the teacher to rephrase the question in a simper language they could understand. This is what Simachenya (2017) also noted that teachers were using the regional language while learners were responding in the languages they were familiar which was not the regional language. Therefore, teachers are now dictated by the classroom linguistic situation to respond to the learners' linguistic needs. Further, Nyimbili and Mwanza (2021) argue that the use of a regional language to cater for linguistic grouping in a province and across districts does not represent the real sociolinguistic that exist in the communities, schools and homes where the learners come from. They argue that the teaching of literacy to learners whose first language of instruction is not the regional language is faced with the failure to use the teaching and learning materials effectively as they are in a different language alien to the learners. Consistent with this study, the teachers in Petauke are also driven by the linguistic needs of the learners which has to be appreciated if they have to make their academic dreams achieved. In this context, we can present that language is the power to present knowledge in a classroom and the learners are realising this need hence they are no longer quiet but always asking for the right knowledge in the familiar language.

The study also found that when Nsenga was used in the teaching, learners became interested in their local language, and they wrote their language more than Cinyanja. This can be linked to the emergent literacy development which the learners have, and the regional language want to supress. This view is also supported by MOE (2014) who stated that since learners come from different language backgrounds, it is very important that teachers conduct oral language lessons in order to expand their learners' working vocabulary in familiar languages which are used for instruction. These policy views seem to conflict with the reality. It is not clear with the language in which the oral language lessons should be conducted and the extent to which such languages should be used. In this case, there is need for languages to be defined in these regions so that teachers are helped in understanding the policy and respond to the new society which is in their classrooms.

\section{CONCLUSION}

It can be concluded that the teachers' perception on the implementation of the use of familiar language in selected Primary Schools in Petauke District was positive because the usage of Cinyanja as an instructional language was high in the primary schools due to the policy restriction while the usage of Nsenga as an instructional language was as high due to the sociolinguistic situation in the classrooms and this lead to the teachers and learners preferring to use Nsenga as their language of instruction. The realised benefits of the use of Nsenga in the teaching to the Nsenga learners provided the learners with the practical understanding of the content the teacher was teaching about. The other benefits were that teachers were forced to use Nsenga in their teaching because learners provided answers in Nsenga instead of the Cinyanja which was not familiar to them. Nsenga was used in the teaching, learners became interested in their local language, and they wrote their language more than Cinyanja. This can be linked to the emergent literacy development which the learners have, and the regional language want to supress. This then leaves space to enhance translanguaging in such schools so as to realise the full potential of the learners and their languages.

\section{REFERENCES}

Banda, F.and Mwanza, D. S. (2017). Language-in-education Policy and Linguistic Diversity in Zambia: An Alternative Explanation to Low Reading Levels among Primary School Pupils. In Banja MadalitsoKhulupirika (ed). Selected Readings in Education, 109- 132. Lusaka: University of Zambia Press.

Chinyama, M. (2016). The Effect of using Bemba as Medium of Instruction (MoI) on the Reading Levels of Grade Two Pupils in a Predominantly NamwangaSpeaking area in Nakonde District. (Unpublished Masters DissertationSubmitted to The University of Zambia, Lusaka).

Cummins, J. (2009). Transformative multiliteracies pedagogy: School-based strategies for closing the achievement gap. Multiple Voices for Ethnically Diverse Exceptional Learners, 11, 38-56. 
The Practicality of using Indigenous Language (Nsenga) as Medium of Instructing at Grade 1-4 in Selected Primary Schools of Petauke District

García, O. (2009). Bilingual education in the 21st century: A global perspective. Malden, MA and Oxford: Basil/Blackwell.

Mkandawire, S. B. (2017). Familiar Language Based Instruction Versus Unfamiliar Language for the Teaching of Reading and Writing Literacy Skills: A Focus on Zambian Languages and English at Two Primary School in Lusaka. Zambia Journal of Language Studies, 1(1) pp. 53-81

Ministry of Education (2014). Education Curriculum Framework 2013. Lusaka: Curriculum Development Centre

Mwanza D. S (2012). The Language of Initial Literacy in a Cosmopolitan Environment: A Case of Cinyanja in Lusaka District. (Unpublished Masters Dissertation. University of Zambia, Lusaka).

Mwanza, D. S. (2017). Implications of Teacherse Attitudes Towards un-official Languages on English Language Teaching in Multilingual Zambia. Journal of Language Studies, 1 (1): 101-124.

Mwanza, D.S. (2020). In search of High Literacy Levels in Zambian Primary Schools: Does Duration of Mother Tongue Instruction before Transitioning into a Second Language Matter. International Journal of Education and Research. 8 (2): 119-134.

Mwanza, D.S. (2020). Critical Reflections on the Zambian Education System and the Teaching of English in Post-Colonial Zambia. English Literature and Language Review. 6 (2) pp. 15-23.

Nyimbili, F. (2017). The Usage of Learner Centred Techniques in the Teaching of English Language In the Secondary Schools of Lundazi District. International Journal of Humanities Social Sciences and Education (IJHSSE), 5(3) pp. 143-149.

Nyimbili, F. and Mwanza, D. S. (2020). Quantitative and qualitative benefits of translanguaging pedagogic practice among first graders in multilingual classrooms of Lundazi district in Zambia. Multilingual Margins 2020, 7(3): 69-83

Nyimbili, F. and Mwanza, D. S. (2021). Translanguaging Challenges faced by Teachers and Learners in First Grade Multilingual Literacy Classrooms in Zambia. International Journal on Studies in English Language and Literature (IJSELL), 9(3) pp. 20-31

Phiri, V. (2012). Teachers' Perception on Factors which Prevent some Grade One Learners from Breaking Through to Initial Literacy in the Primary Schools of Solwezi. (Unpublished Masters Dissertation. University of Zambia, Lusaka).

Simachenya, M. M. (2017). Language Practices in A Multilingual Classroom Situation: A Case of Selected Primary Schools in Livingstone Urban. (Unpublished Masters Dissertation. University of Zambia, Lusaka).

Tambulukani, G. K. (2014). First Language of Initial Reading: Blessing or Curse for the Zambian Children under Primary Reading Program. (Unpublished PhD. Dissertation. The University of Zambia).

Zimba, S. (2011). The Effects of Nyanja as a Language of Initial Literacy in a Predominantly Tumbuka Speaking Area: The Case of Lumezi Area of Lundazi District. Unpublished Masters Dissertation. The University of Zambia. 
The Practicality of using Indigenous Language (Nsenga) as Medium of Instructing at Grade 1-4 in Selected Primary Schools of Petauke District

\section{AUTHORS' BIOGRAPHY}

Tembo Gerald Major, is a Master holder in Education Management from the University of Africa, Guidance and Counselling Practitioner, Personal, Social and Citizenship Educator and an Educator.

Nyimbili Friday, is a Ph. D student at the University of Zambia, School of Education, department of Language and Social Science Education, proof reader and Part Time lecturer at Chalimbana University, Languages department.

Citation: Tembo Gerald Major \& Nyimbili Friday. "The Practicality of using Indigenous Language (Nsenga) as Medium of Instructing at Grade 1-4 in Selected Primary Schools of Petauke District" International Journal on Studies in English Language and Literature (IJSELL), vol 9, no. 10, 2021, pp. 1-10. doi: https://doi.org/ 10.20431/2347-3134.0910001.

Copyright: (c) 2021 Authors. This is an open-access article distributed under the terms of the Creative Commons Attribution License, which permits unrestricted use, distribution, and reproduction in any medium, provided the original author and source are credited. 